\title{
SISTEM INFORMASI TABUNGAN SISWA BERBASIS WEB PADA SEKOLAH MENENGAH KEJURUAN (SMK) NUSA PUTRA KOTA TANGERANG
}

\author{
Suwarto ${ }^{1}$ \\ Nasril Sany ${ }^{2}$ \\ Eka Indriani ${ }^{3}$ \\ Dosen STMIK Raharja ${ }^{1}$, Dosen AMIK Raharja ${ }^{2}$, STMIK Raharja Jurusan Sistem \\ Informasi $^{3}$ \\ Jl. Jendral Sudirman no.40, Modern, Cikokol Tangerang ${ }^{1,2}, 3$ \\ Email: suwarto@ raharja.info ${ }^{1}$,nasril.sany@raharja.info ${ }^{2}$,eka.indriani@raharja.info ${ }^{3}$
}

\begin{abstract}
ABSTRAK
Sekolah Menengah Kejuruan (SMK) Nusa Putra Kota Tangerang hanyalah salah satu sekolah yang belum menerapkan teknologi (by system) secara menyeluruh. Diantaranya yaitu tabungan siswa. Dalam sistem yang berjalan saat ini pembayaran tabungan masih dilakukan bersamaan (dijadisatukan) dengan pembayaran SPP yakni satu bulan sekali dan data dimasukkan ke dalam Microsoft Access 2010 oleh satu orang bendahara sekolah dimana memiliki kemungkinan akan terjadi kesalahan atau ketidaktepatan dalam memasukkan nominal tabungan, siswa tidak dapat mengetahui jumlah saldo yang dimiliki, tidak memungkinkan para siswa untuk dapat menabung setiap harinya dan hanya dapat dipergunakan di kelas XII (dua belas). Sehingga diperlukan adanya sistem tersendiri bagi tabungan siswa yaitu sistem informasi tabungan siswa berbasis web. Penelitian ini menggunakan metode analisa PIECES (Performance, Information, Economy, Control, Efficiency, Service), elisitasi kebutuhan sistem serta pemodelan sistem menggunakan UML (Unified Modeling Language) untuk menggambarkan secara visualisasi, yang selanjutnya diimplementasikan dengan bahasa pemrograman PHP (Hypertext Preprocessor) dengan basis data MySQL sebagai database yang digunakan. Sistem Informasi Tabungan Siswa berbasis web ini diharapkan mampu mengatasi permasalahan yang ada, mengingat manfaat dari tabungan ini cukup penting untuk para siswa serta sekolah untuk menuju kepada cyber school.
\end{abstract}

Kata Kunci : Sistem, Informasi, Tabungan, Siswa, Web

\begin{abstract}
Vocational High School (SMK) Nusa Putra Kota Tangerang is the one of schools that has not implemented the technology (by systems) yet overall. One of those is the students savings. In the current system, the payment of savings still undertaken at the same time (adjoined) by the payment of SPP which is once a month and data entered into Microsoft. Access 2010 by one school treasurer where having the possibility of going to happen a fault or inaccuracy in providing input to the nominal savings, students could not know the count of their own balance, can't be able to save their money every single day and those savings can only be used in twelfh grade. So that means there needs a seperate system for students savings namely the design of web-based information system student savings. This research is using the analys method PIECES (Performance, Information, Economy, Control, Efficiency, Sefvice), system requirement elititation and the system modeling is using UML (Unified Modeling Language) to describe in visualization which is implemented by PHP (Hypertext Preprocessor) as a programming language with MySQL as a database. Web-based Information System Student Savings is expected can solve the
\end{abstract}


problems connsidering the benefit of these savings is important enough to students and school to towards the cyberschool.

Key words : Sytem, Information, Savings, Student, Web

\section{PENDAHULUAN}

Hampir semua aspek kehidupan memanfaatkan teknologi informasi untuk memenuhi kebutuhan yang ada. Begitu pun hal tersebut berlaku dalam bidang pendidikan. Mulai dari tingkat dasar sampai dengan perguruan tinggi diharapkan bahkan diharuskan untuk menerapkan teknologi dalam proses belajar mengajar. Tidak hanya sampai disitu tetapi juga dalam pelayanan administrasi atau pelayanan lainnya yang berhubungan dengan para siswa dan para pengajar pun demikian dengan tujuan mempermudah dalam proses belajar mengajar, proses pengolahan data sampai dengan disajikannya suatu laporan yang akurat.

Sekolah Menengah Kejuruan (SMK) Nusa Putra Kota Tangerang adalah sekolah kejuruan swasta yang memiliki dua jurusan yaitu Keuangan (KU) dan Teknik Komputer dan Jaringan (TKJ) yang terdiri dari 336 siswa serta 42 guru dan staff. Sekolah ini adalah salah satu sekolah swasta yang belum menerapkan teknologi (by system) secara menyeluruh dalam hal pelayanan administrasi para siswa dan pengajarnya. Baik itu pendaftaran siswa, pembayaran SPP, tabungan, absensi dan lain sebagainya. Siswa kelas 10 Sekolah Menengah Kejuruan (SMK) Nusa Putra Kota Tangerang sudah mulai diwajibkan untuk menabung satu bulan sekali dimana nantinya hasil dari tabungan tersebut bisa dipergunakan untuk biaya-biaya di kelas 12. Mengingat di sekolah swasta memang dibutuhkan biaya yang cukup besar di kelas tingkat tersebut karena tidak disubsidi menyeluruh oleh pemerintah.

Sistem tabungan yang berjalan saat ini di Sekolah Menengah Kejuruan (SMK) Nusa Putra Kota Tangerang yaitu dilakukan bersamaan dengan pembayaran SPP yakni satu bulan sekali dan hanya di input menggunakan Microsoft Access 2010 oleh satu orang bendahara sekolah yang kemungkinan akan terjadi kesalahan atau ketidaktepatan dalam memasukkan nominal tabungan. Serta tabungan tersebut hanya dapat dipergunakan pada saat kelas 12 (dua belas) dan hanya untuk membayar biaya-biaya ujian selain itu tidak diperbolehkan.

Melihat bahwa tabungan ini cukup penting untuk para siswa serta mengingat sekolah ini memang sedang dalam proses untuk menuju kepada cyber school, ada baiknya tabungan tersebut memiliki sistem sendiri dan berbasis web agar para siswa pun bisa ikut ambil bagian dalam sistem tabungan tersebut serta tidak terbatas hanya menabung satu bulan sekali tetapi juga kapan pun para siswa ingin menabung dan bisa dipergunakan untuk pembayaran keperluan lain yang berkaitan dengan kegiatan sekolah.

Rumusan permasalahan penelitian yang dapat ditarik adalah sebagai berikut :

1. Bagaimana sistem tabungan siswa yang berjalan saat ini di Sekolah Menengah Kejuruan (SMK) Nusa Putra Kota Tangerang?

2. Apa saja kekurangan serta hambatan dari sistem yang berjalan saat ini?

3. Bagaimana rancangan sistem tabungan yang diusulkan untuk memecahkan permasalahan tersebut? 


\section{TUJUAN PENELITIAN}

Terdapat beberapa tujuan dalam penyusunan laporan penelitian ini, yaitu sebagai berikut :

1. Mengetahui sistem tabungan siswa yang berjalan saat ini di Sekolah Menengah Kejuruan (SMK) Nusa Putra Kota Tangerang.

2. Mengetahui apa saja kekurangan serta hambatan yang terjadi apabila menggunakan sistem yang berjalan saat ini.

3. Mengetahui solusi dari pada permasalahan yang terjadi.

\section{MANFAAT PENELITIAN}

Dari penelitian yang telah dilakukan terdapat beberapa manfaat yang dihasilkan, diantaranya :

1. Sebagai bahan masukan yang dapat mendukung peningkatan status akreditasi sekolah untuk menuju kepada cyber school.

2. Sebagai sarana untuk para siswa agar lebih rajin untuk menabung.

3. Sebagai sarana untuk dapat meringankan para siswa dalam membayar biayabiaya yang berkaitan dengan kegiatan sekolah.

\section{LANDASAN TEORI}

\section{Sistem}

"Satu kesatuan yang terbentuk dan secara terorganisasi saling berhubungan berdasarkan fungsi-fungsi suatu himpunan dari berbagai bagian atau elemen." (Bambang Hartono, 2013) [1]

\section{Sistem Infomasi}

"Informasi yang tersimpan yang berasal dari suatu pengolahan data dimana pengolahan tersebut dikelola oleh gabungan dari komputer dan user." (Susanto, Azhar, 2013) [2]

\section{Tabungan Siswa}

"Tabungan siswa merupakan tabungan program pendidikan bagi para orang tua untuk mempersiapkan masa depan anak secara terencana, murah, aman dan pasti." (Hendra Purnama, 2014) [3]

\section{UML (Unified Modelling Language)}

"Diagram dan teks-teks pendukung mengenai sebuah sistem yang menggunakan bahasa visual sebagai pemodelan dan komunikasi." (Haryanta, 2017) [4]

\section{Website}

"Teknologi sistem informasi yang menghubungkan data dari banyak sumber serta layanan yang beragam macamnya di internet dimana ini merupakan suatu terobosan baru dalam dunia teknologi sistem informasi tersebut. Web cepat sekali populer di lingkungan pengguna internet karena kemudahan yang diberikan kepada pengguna internet untuk melakukan penelusuran, penjelajahan dan pencarian informasi.” (Sutopo Priyo, 2016) [5] 


\section{PHP}

"PHP merupakan server-side programming, yaitu bahasa pemrograman yang diproses di sisi server. Fungsi utama PHP dalam membangun website adalah untuk melakukan pengolahan data pada database. Data website akan dimasukkan ke database, diedit, dihapus dan ditampilkan pada website yang diatur oleh PHP." (Abdulloh, 2016) [6]

\section{Xampp}

"Salah satu paket installer yang berisi Apache yang merupakan web server tempat menyimpan file-file yang diperlukan website dan phpmyadmin sebagai aplikasi yang digunakan untuk perancangan database MySQL." (Abdulloh, 2016) [6]

\section{Phpmyadmin}

"Phpmyadmin merupakan aplikasi berbasis web yang digunakan untuk membuat database MySQL sebagai tempat untuk menyimpan data-data website." (Abdulloh, 2016) [6]

\section{MySQL}

"MySQL yaitu salah satu jenis database server yang sangat terkenal. Kepopulerannya disebabkan MySQL menggunakan SQL sebagai bahasa dasar untuk mengakses database-nya. MySQL termasuk jenis RDBMS (Relational Database Management System).” (Sutopo Priyo, 2016) [5]

\section{METODOLOGI PENELITIAN}

\section{Metode Pengumpulan Data}

\section{Observasi}

Observasi dilakukan pada Sekolah Menengah Kejuruan (SMK) Nusa Putra Kota Tangerang pada bagian Administrasi Keuangan atau bendahara SMK serta Tata Usaha. Berawal dari dilakukannya pengamatan menyeluruh terhadap sistem yang sedang berjalan dalam proses tabungan siswa, kemudian mempelajari kekurangan-kekurangan yang ada, setelah di ambil kesimpulan sementara mengenai masalah-masalah yang ada secara menyeluruh kemudian mendefinisikan masalah tersebut.

\section{Wawancara}

Metode untuk mendapatkan data dan keterangan mengenai data sekolah tersebut serta mengenai kebutuhan sistem yang akan dirancang dengan cara mewawancara atau membuat tanya jawab dengan bagian Administrasi Keuangan, Tata Usaha dan Kurikulum pada sekolah tersebut. Dalam hal ini pihak yang diwawancarai yaitu Bendahara Ibu Harjati, Bapak Jailani sebagai Kepala Tata Usaha dan Bapak Indra sebagai Kepala Kurikulum pada Sekolah Menengah Kejuruan (SMK) Nusa Putra Kota Tangerang.

\section{Studi Pustaka}

Untuk mendapatkan informasi yang berkaitan dengan judul skripsi ini maka peneliti akan mengambil beberapa data berupa data siswa/siswi, data tabungan yang saat ini sedang berjalan, dan lain sebagainya di Sekolah Menengah Kejuruan (SMK) Nusa Putra Kota Tangerang. 


\section{Metode Analisa}

Setelah proses pengumpulan data dilaksanakan melalui beberapa metode, maka data yang sudah ada akan diolah dan dianalisa supaya mendapatkan hasil akhir yang bermanfaat pada penelitian ini. Peneliti menggunakan metode analisa PIECES (Performance, Information, Economy, Control/Security, Efficiency, Service) yang digunakan untuk menganalisa sistem yang berjalan dari segi kinerja apakah sudah efisien, informasi yang dihasilkan, keamanan dari sistem tersebut yang tidak memakan biaya yang cukup besar sampai kepada pelayanan yang diberikan.

\section{Metode Perancangan}

Perancangan sistem informasi tabungan siswa yang akan dibuat menggunakan metode Unified Modeling Language (UML) yang akan dituangkan dalam Usecase Diagram dan Class Diagram dengan menggunakan alat bantu (tool) berupa Visual Paradigm for UML 6.4 Enterprise Edition. Bahasa pemrograman yang digunakan yaitu PHP dengan framework YII serta penjabaran rancangan basis data dan spesifikasinya menggunakan beberapa software yaitu XAMPP, MYSQL, Chrome.

\section{LITERATURE REVIEW}

\section{Penelitian yang dilakukan oleh Hendra Purnama, Wahyudin dan Rina Kurniawati (2014)}

Penelitian tersebut berjudul "Perancangan Program Aplikasi Tabungan Siswa Sekolah Dasar Negeri Cipancar IV Dengan Menggunakan Pendekatan Metodologi Rapid Application Development". Dalam penelitian ini dijelaskan bahwa proses tabungan yang berjalan saat ini masih dikerjakan secara manual baik itu pencatatan dan penyimpanan data ditulis di dalam buku serta perhitungannya masih menggunakan alat bantu kalkulator. Penelitian ini dilakukan untuk mengatasi masalah-masalh yang timbul dari sistem yang berjalan saat ini dengan membuat sebuah perangkat lunak dimana metodologi yang digunakan ialah Rapid Application Development. Tool yg digunakan adalah Micrososf Visio, database Microsoft Acces serta bahasa pemrograman Microsoft Visual Basic 6.0.

\section{Penelitian yang dilakukan oleh Ardi Wijaya dan Army Martia Harjuna (2017)}

Penelitian tersebut berjudul "Perancangan Program Aplikasi Tabungan Menggunakan Server NGINX (Studi Kasus Madrasah Ibtidayah Negeri 01 Kota Bengkulu". Dalam penelitian ini dijelaskan bahwa sistem pengelolaan data tabungan yang berjalan saat ini masih dikerjakan secara manual pencatatan dan penyimpanan data ditulis di dalam buku, dan perhitungannya masih dikerjakan dengan alat bantu kalkulator. Pada penelitian ini akan dibangun sebuah sistem basis data yang menggunakan server NGINX. NGiNX adalah sebuah server HTTP dan reserve proxy gratis berbasis opensource. 
3. Penelitian yang dilakukan oleh Santi Yurike Dewi, Tarih Tresnati, Eva Misfah Bayuni (2017)

Penelitian tersebut berjudul "Pengaruh Relationship Quality Terhadap Loyalitas Nasabah Tabungan Siswa di BRI Syariah Kantor Kas UNISBA”. Dalam penelitian ini dijelaskan bagaimana pengaruh hubungan antara kualitas terhadap loyalitas nasabah yang menabung di BRI Syariah Kantor Kas UNISBA. Analisis deskriptif dengan pendekatan kuantitatif menggunakan software SPSS versi 22.0. Teknik yang digunakan untuk mengumpulkan data adalah kuisioner, wawancara dan studi kepustakaan.

\section{HASIL DAN PEMBAHASAN}

\section{Perancangan Sistem}

Sistem ini dirancang dengan menggunakan alat bantu (tool) UML (Unified Modelling Language) dengan bantuan diagram usecase.

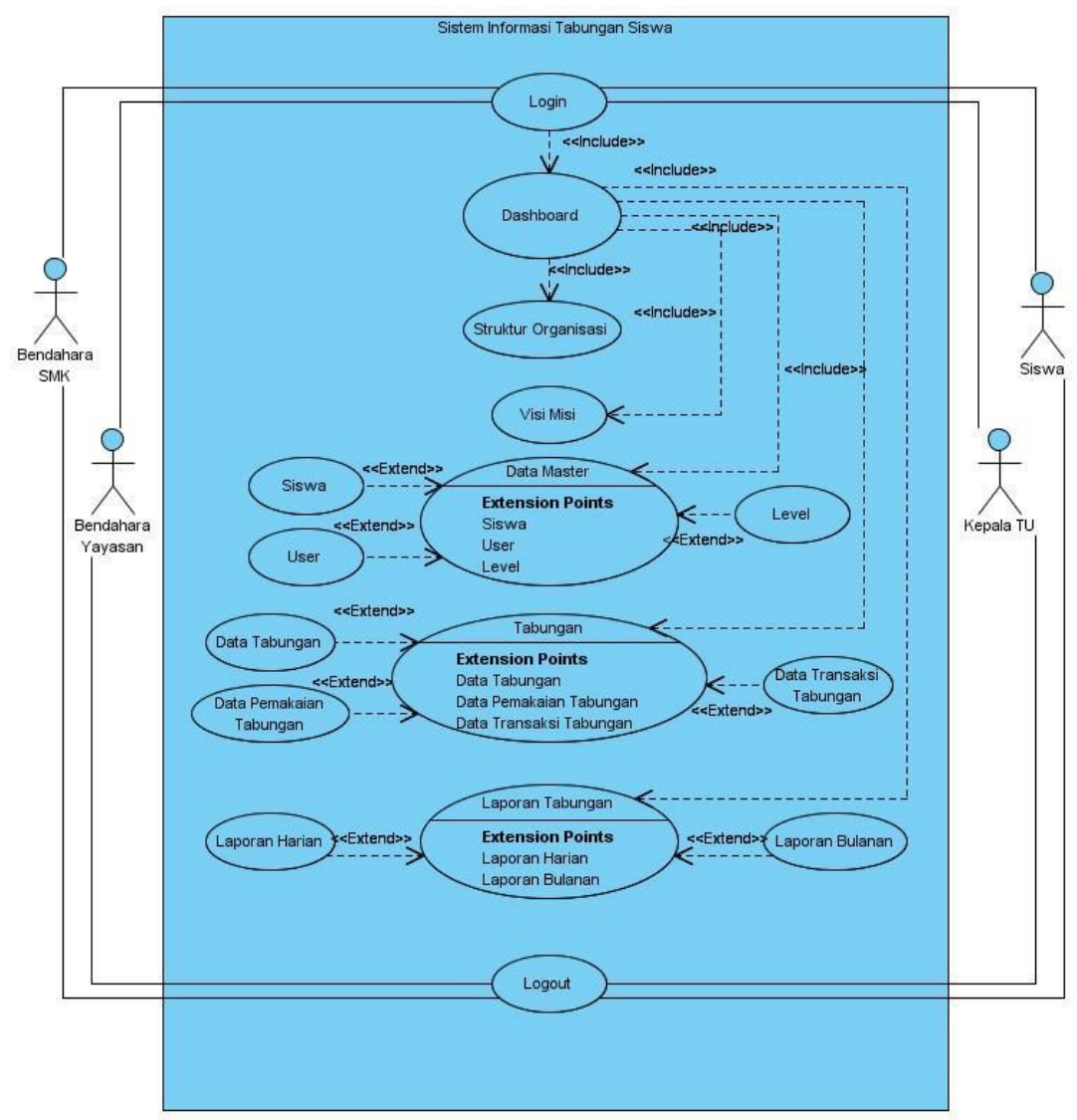

\section{Gambar 1. Usecase Diagram Sistem Informasi Tabungan Siswa}

Berdasarkan gambar diatas dapat dijelaskan :

1. Terdapat 4 aktor yaitu Bendahara SMK, Bendahara Yayasan, Siswa dan Kepala TU.

2. Terdapat 11 usecase.

3. 3 extend yaitu menu Data Master, Tabungan dan Laporan Tabungan. 


\section{Perancangan Basis Data (Database)}

Rancangan basis data pada sistem informasi tabungan siswa berbasis web pada Sekolah Menengah Kejuruan (SMK) Nusa Putra Kota Tangerang ini digambarkan dengan menggunakan pemodelan UML yaitu class diagram. Berikut adalah class diagram sistem tersebut.

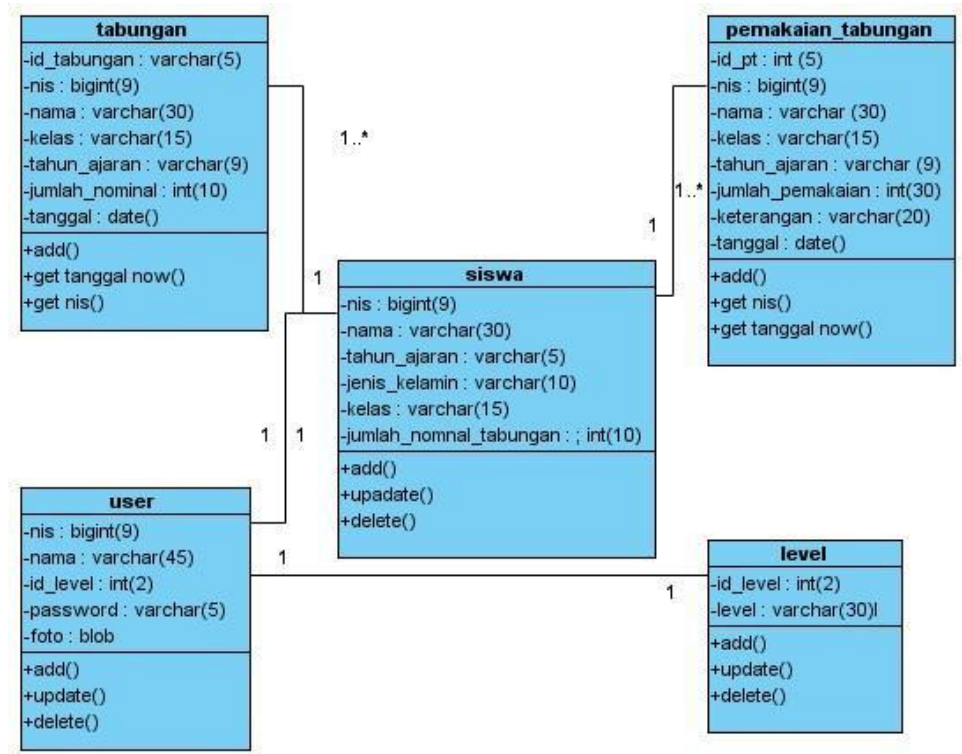

Gambar 2. Class Diagram

\section{Spesifikasi Basis Data (Database)}

Spesifikasi basis data menjelaskan nama, field, type data, size dan keterangan field kunci. Berikut ini merupakan spesifikasi tabel pada sistem yang diusulkan.

Tabel 1. Data Siswa

\begin{tabular}{|l|l|l|l|}
\hline Siswa & Type & $\begin{array}{l}\text { Field } \\
\text { Size }\end{array}$ & Keterangan \\
\hline Nama Field & bigint & 9 & Primary Siswa \\
\hline Nis & varchar & 30 & Nama Siswa \\
\hline tahun_ajaran & varchar & 9 & Tahun ajaran siswa \\
\hline jenis_kelamin & varchar & 10 & Jenis kelamin \\
\hline Kelas & varchar & 15 & Kelas siswa \\
\hline jumlah_nominal_tabungan & int & 10 & Nominal tabungan \\
\hline
\end{tabular}

Tabel 2. Pemakaian Tabungan

\begin{tabular}{|l|l|l|l|}
\hline pemakai_tabungan & Type & $\begin{array}{l}\text { Field } \\
\text { Size }\end{array}$ & Keterangan \\
\hline Nama Field & Int & 5 & $\begin{array}{l}\text { id } \\
\text { tabungan }\end{array}$ \\
\hline id_pt & bigint & 9 & NIS siswa \\
\hline Nis & varchar & 30 & Nama siswa \\
\hline Nama & \multicolumn{3}{|l}{} \\
\hline
\end{tabular}




\begin{tabular}{|l|l|l|l|} 
tahun_ajaran & varchar & 9 & Tahun ajaran siswa \\
\hline Kelas & varchar & 15 & Kelas siswa \\
\hline jumlah_pemakaian & Int & 10 & jumlah pemakaian \\
\hline Keterangan & varchar & 20 & Keterangan \\
\hline Tanggal & date & - & $\begin{array}{l}\text { Tanggal pemakaian } \\
\text { tabungan }\end{array}$ \\
\hline
\end{tabular}

Tabel 3. Tabungan

\begin{tabular}{|l|l|l|l|}
\hline \multicolumn{5}{|c|}{ Tabungan } \\
\hline Nama Field & Type & $\begin{array}{l}\text { Field } \\
\text { Size }\end{array}$ & Keterangan \\
\hline id_tabungan & varchar & 5 & Primary tabungan \\
\hline Nis & bigint & 9 & Nis Siswa \\
\hline Nama & varchar & 30 & Nama siswa \\
\hline Kelas & varchar & 15 & Kelas siswa \\
\hline tahun_ajaran & varchar & 9 & Tahun ajaran siswa \\
\hline jumlah_nominal & int & 10 & Jumlah nominal \\
\hline Tanggal & date & & Tanggal menabung \\
\hline
\end{tabular}

Tabel 4. Level

\begin{tabular}{|l|l|l|l|}
\hline \multicolumn{4}{|c|}{ Level } \\
\hline Nama Field & Type & $\begin{array}{l}\text { Field } \\
\text { Size }\end{array}$ & Keterangan \\
\hline id_level & int & 2 & Id level \\
\hline Level & varchar & 30 & nama Level \\
\hline
\end{tabular}

Tabel 5. User

\begin{tabular}{|l|l|l|l|}
\hline \multicolumn{4}{|c|}{ User } \\
\hline Nama Field & Type & $\begin{array}{l}\text { Field } \\
\text { Size }\end{array}$ & Keterangan \\
\hline Nis & bigint & 9 & nis \\
\hline Password & varchar & 5 & Password \\
\hline id_level & int & 2 & id level \\
\hline Nama & Varchar & 45 & nama user \\
\hline Foto & Blob & & foto user \\
\hline
\end{tabular}

\section{IMPLEMENTASI}

\section{Tampilan Halaman Login}

Setiap user wajib untuk login terlebih dahulu sebelum dapat mengakses Sistem Informasi Tabungan Siswa seperti pada gambar dibawah ini. 


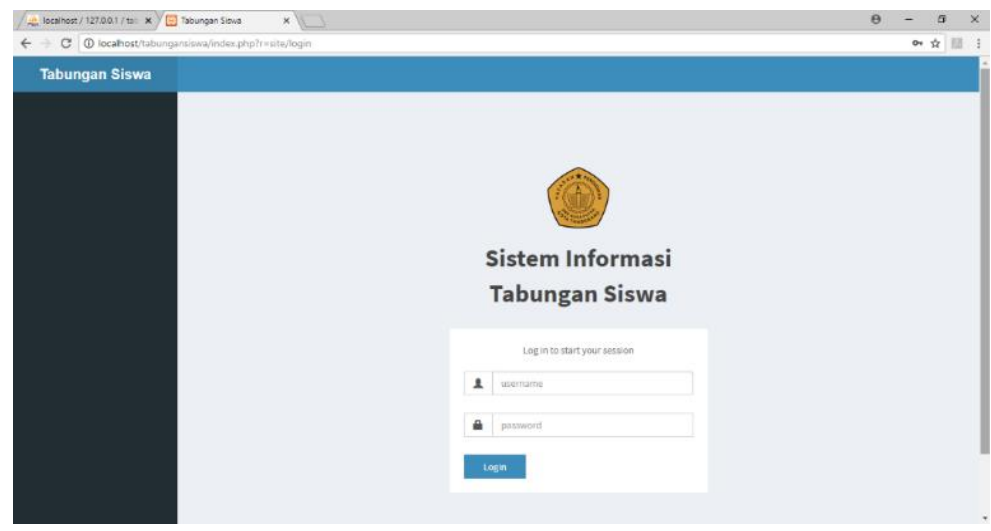

Gambar 3. Tampilan Halaman Login

\section{Tampilan Halaman Dashboard}

Setelah berhasil login maka akan tampil halaman seperti gambar dibawah ini.

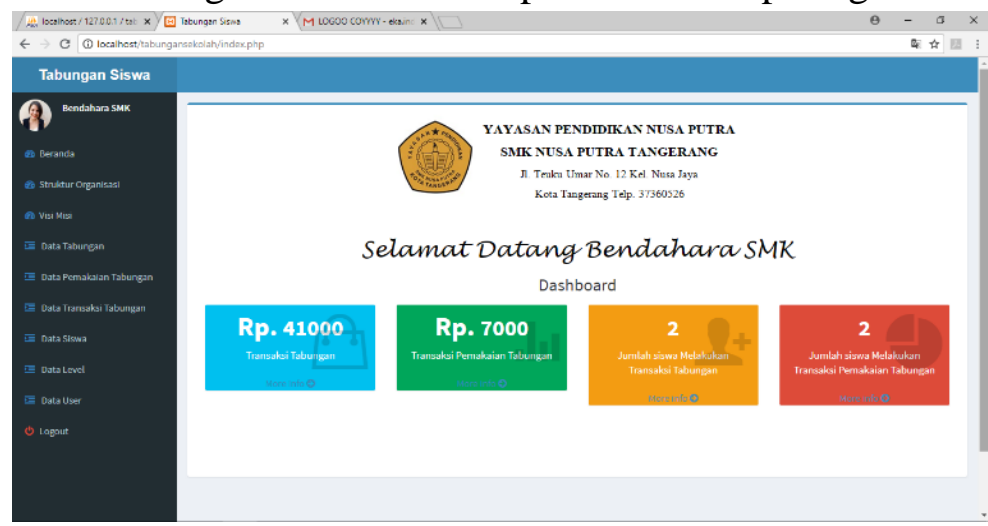

Gambar 4. Tampilan Halaman Dashboard

\section{Tampilan Tabel Data Tabungan}

Dibawah ini merupakan tampilan dimana daftar dari tabungan para siswa tertera.

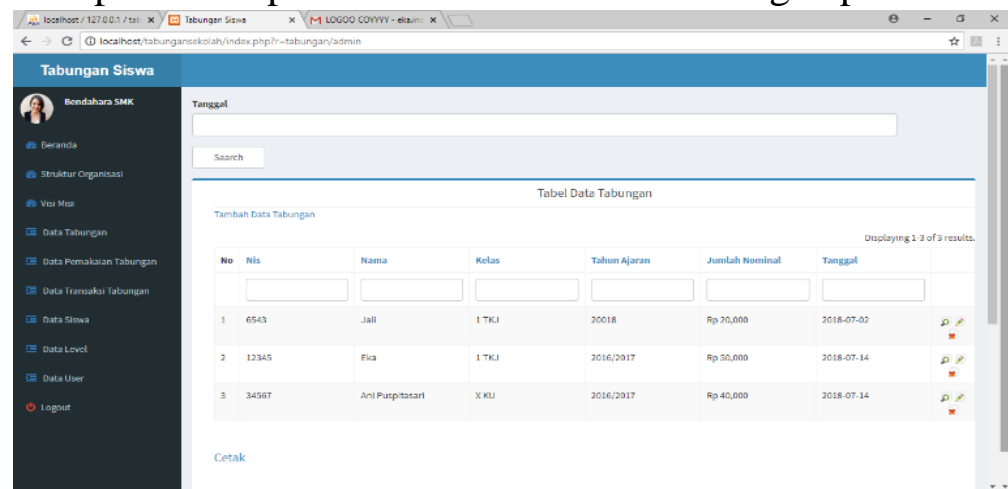

Gambar 5. Tampilan Tabel Data Tabungan

\section{Tampilan Tabel Data Pemakaian Tabungan}

Dibawah ini merupakan tampilan dimana daftar dari pemakaian tabungan para siswa tertera. 


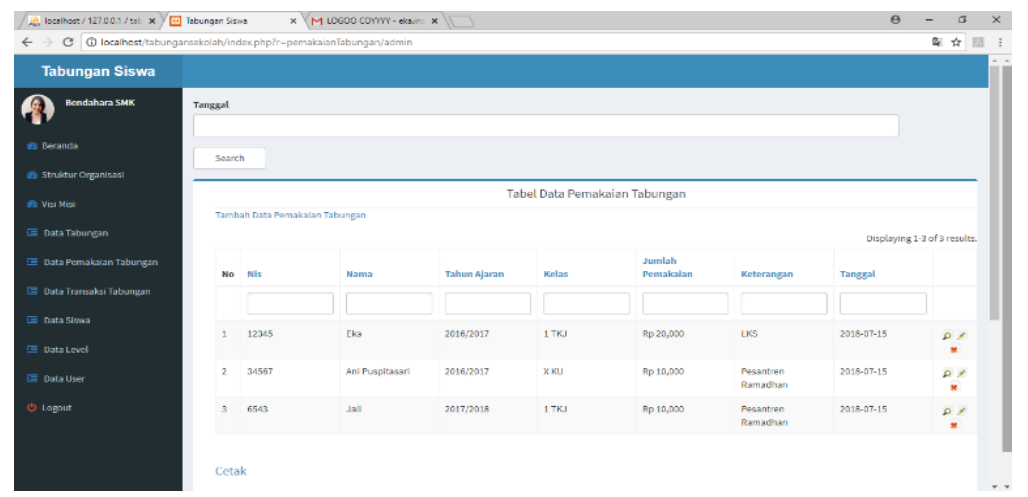

Gambar 6. Tampilan Tabel Data Pemakaian Tabungan

\section{Tampilan Tabel Data Transaksi Tabungan}

Berikut adalah tampilan data transaksi tabungan dimana tertera seluruh transaksi para siswa termasuk di dalamnya saldo tabungan yang dimiliki.

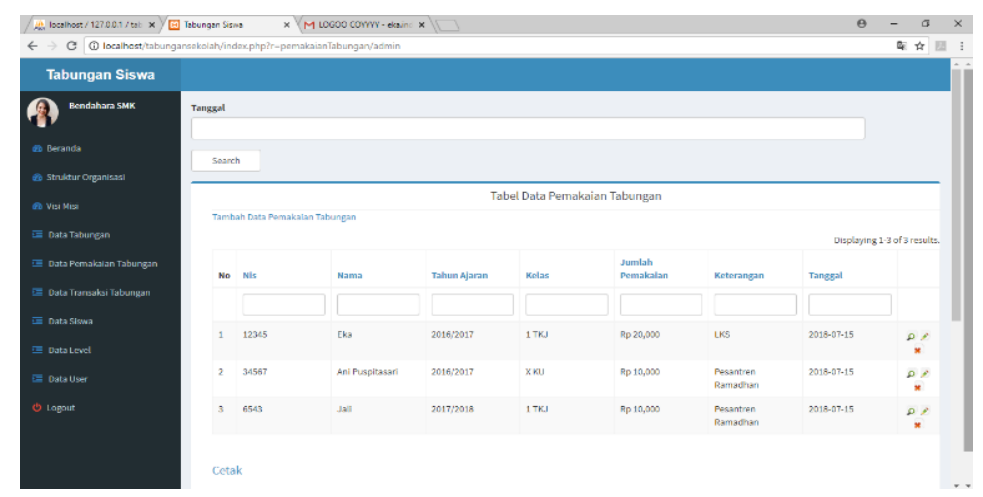

Gambar 7. Tampilan Tabel Data Transaksi Tabungan

\section{Tampilan Tambah Data Tabungan}

Berikut adalah tampilan yang akan muncul jika Bendahara SMK akan menambah atau menginput jumlah tabungan siswa.

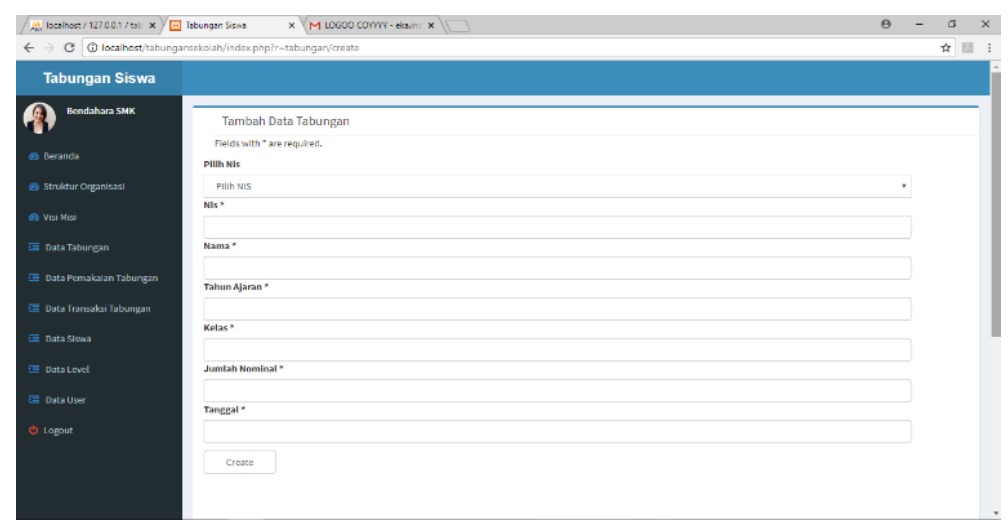

Gambar 8. Tampilan Tambah Data Tabungan

\section{Tampilan Tambah Data Pemakaian Tabungan}

Berikut adalah tampilan yang akan muncul jika Bendahara SMK akan menambah atau menginput jumlah pemakaian tabungan siswa. 


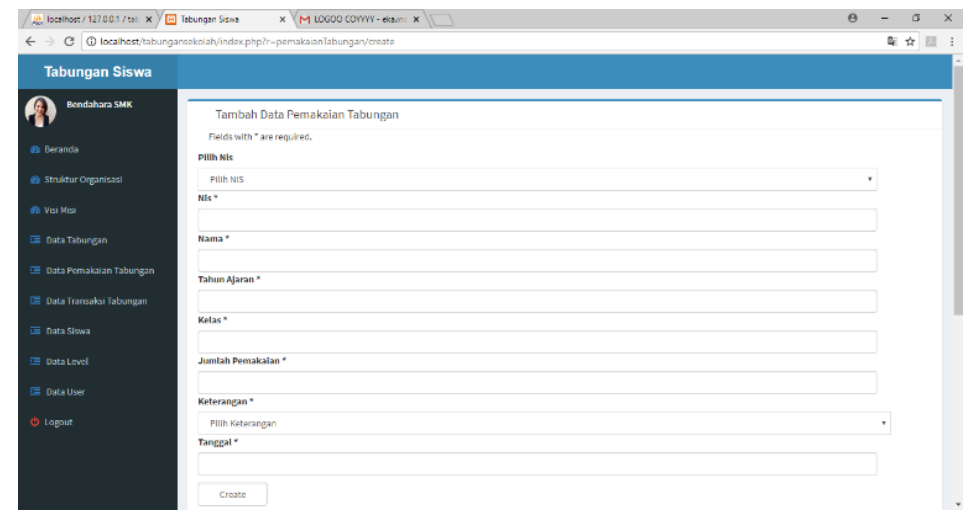

Gambar 9. Tampilan Tambah Data Pemakaian Tabungan

\section{Tampilan Saldo Rekening Tabungan}

Para siswa dapat melihat berapa jumlah saldo tabungan yang mereka miliki seperti pada gambar dibawah ini.

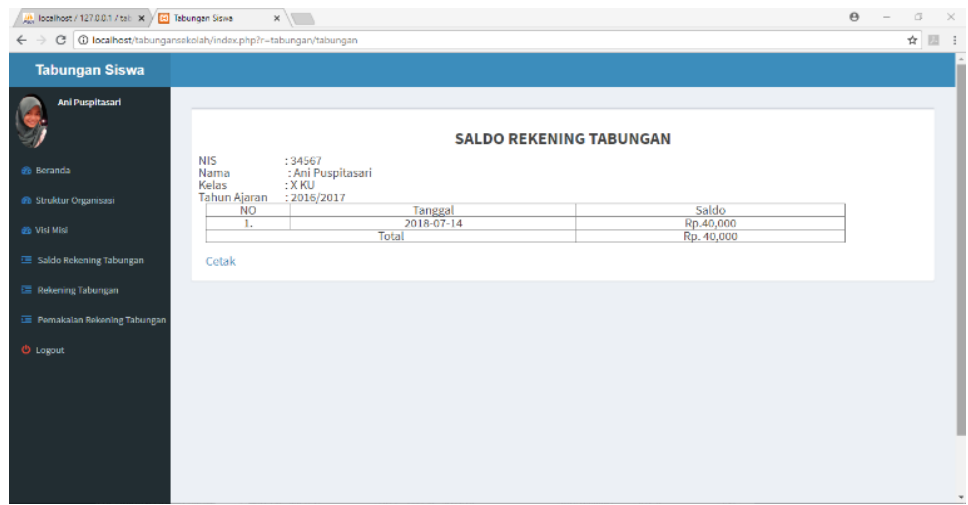

Gambar 10. Tampilan Saldo Rekening Tabungan

\section{Tampilan Rekening Tabungan}

Para siswa dapat melihat daftar tabungan mereka yang telah di-input atau ditambahkan oleh Bendahara SMK.

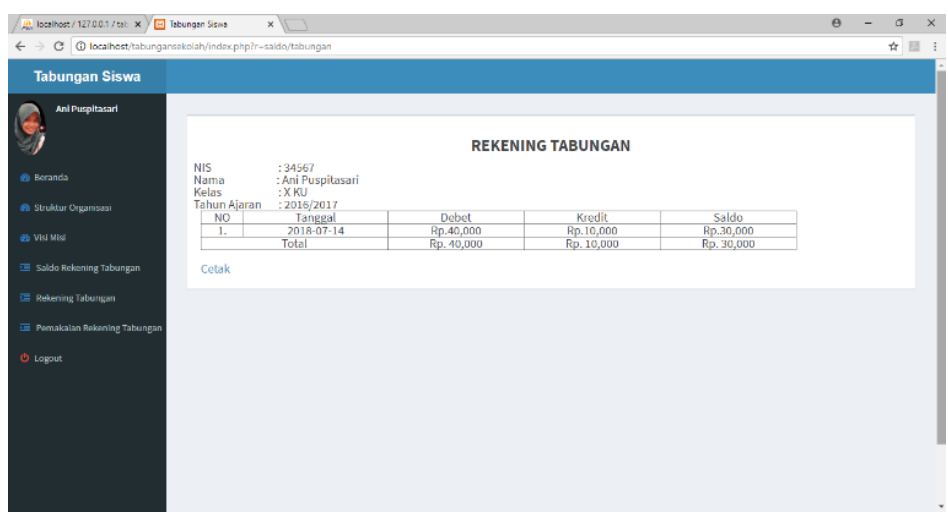

Gambar 11. Tampilan Rekening Tabungan 


\section{Tampilan Pemakaian Rekening Tabungan}

Para siswa dapat melihat daftar pemakaian tabungan mereka yang telah diinput atau ditambahkan oleh Bendahara SMK.

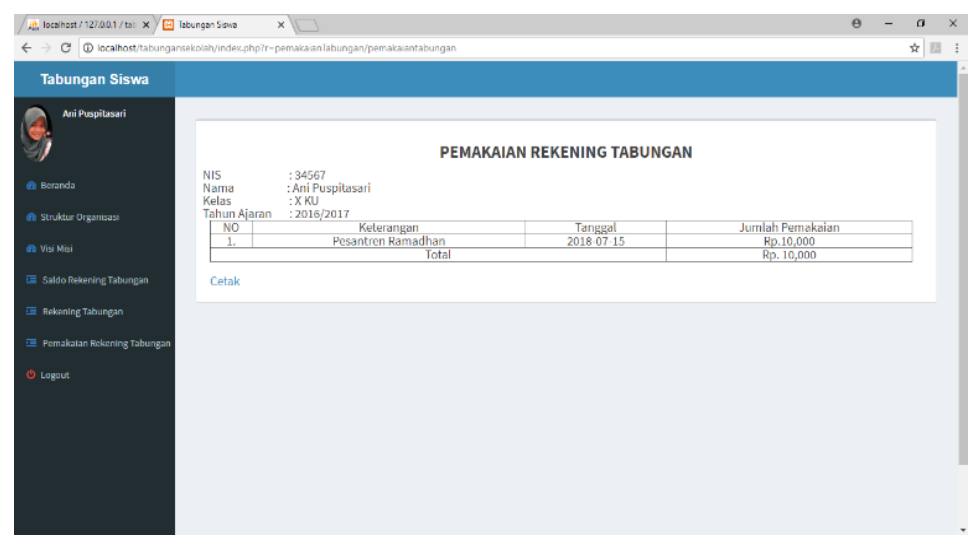

Gambar 12. Tampilan Pemakaian Rekening Tabungan

\section{KESIMPULAN DAN SARAN}

\section{KESIMPULAN}

Berdasarkan pembahasan yang telah diuraikan mengenai sistem tabungan siswa pada Sekolah Menengah Kejuruan (SMK) Nusa Putra Kota Tangerang serta rancangan sistem usulan, maka peneliti dapat mengambil kesimpulan bahwa :

1. Sistem tabungan siswa yang berjalan saat ini masih disatukan dengan tabungan dalam hal pembayarannya dan untuk pencatatan pembayaran masih dilakukan secara semi komputerisasi menggunakan Ms. Access 2010.

2. Yang menjadi kekurangan dari sistem yang berjalan saat ini ialah memiliki kemungkinan akan terjadi kesalahan atau ketidaktepatan dalam memasukkan nominal tabungan dikarenakan pembayaran serta pencatatan tabungan masih dijadisatukan dengan SPP yang dikelola oleh satu orang bendahara dengan menggunakan Ms. Access 2010 yang menurut bendahara itu sendiri cukup sulit untuk digunakan. Para siswa terbatas hanya dapat menabung satu bulan sekali dimana tabungan tersebut pun tidak dapat digunakan selain untuk pembayaran ujian di kelas XII (dua belas) yang mana tujuan dari diadakannya tabungan tersebut belum dapat tercapai secara optimal, dalam hal ini adalah menjadi media para siswa untuk dapat meringankan biaya-biaya yang berkaitan dengan kegiatan sekolah. Para siswa juga tidak dapat mengetahui berapa jumlah saldo tabungan mereka masing-masing dikarenakan dalam buku pembayaran tidak tercantumkan jumlah saldo tabungan tersebut.

3. Rancangan sistem tabungan siswa yang dibuat telah tertera pada pembahasan di atas dimana dalam Sistem Informasi Tabungan Siswa berbasis web ini diharapkan mampu membantu mengatasi permasalahan atau kekurangan dari sistem yang berjalan saat ini serta membantu sekolah untuk menuju kepada cyber school. 


\section{SARAN}

Untuk membuat sistem ini semakin kompleks, diperlukan adanya suatu pengembangan, maka dari itu berikut saran yang akan diberikan :

1. Dapat dikembangkan untuk menjadi bank mini sekolah dimana tidak hanya para siswa saja yang dapat menabung tetapi guru serta staff juga dapat menabung.

2. Dapat dilakukan pengembangan agar para siswa mampu untuk melakukan sendiri proses transaksi tabungan tersebut dalam hal memasukkan data.

3. Dikembangkan menjadi sistem berbasis mobile dengan catatan tetap terkontrol oleh admin dan database dapat terintegerasi dengan pembayaran-pembayaran lainnya yang berkaitan dengan kegiatan Sekolah Menengah Kejuruan (SMK) Nusa Putra Kota Tangerang.

\section{DAFTAR PUSTAKA}

[1] B. Hartono, Sistem Informasi Manajemen Berbasis Komputer, Jakarta: PT Rineka Cipta, 2013.

[2] A. Susanto, Sistem Informasi Akuntansi, Bandung: Lingga Jaya, 2013.

[3] W. R. K. Hendra Purnama, "Perancangan Program Aplikasi Tabungan Siswa Sekolah Dasar Negeri Cipancar IV Dengan Menggunakan Pendekatan Metodologi Rapid Application Development," Jurnal Algoritma, vol. 11, no. $1,2014$.

[4] A. Haryanta dan R. d. A. S. A, "Perancangan Sistem Informasi Perencanaan Dan Pengendalian Bahan Baku Pada Home Industri," Jurnal Sisfotek Global, vol. 7, no. 1, 2017.

[5] P. Sutopo, D. Cahyo dan Z. Arifin, "Sistem Informasi Eksekutif Sebaran Penjualan Kendaraan Bermotor Roda 2 Di Kalimantan Timur Berbasis Web," Jurnal Informatika Mulawarman, vol. 11, no. 1, 2016.

[6] R. Abdulloh, Easy \& Simple Web Programming, Jakarta: PT Elex Media Komputindo, 2016. 